\title{
Does Prosocial Motivation and Psychological Capital Improve Organizational Citizenship Behavior? An Emperical Study Through the Moderating Role of Workplace Incivility
}

Muhammad Nawaz ( $\nabla$ m_nawaz_progressive@yahoo.com )

National College of Business Administration \& Economics https://orcid.org/0000-0002-3719-7914

Ghulam Abid

National College of Business Administration \& Economics

Research article

Keywords: workplace incivility, organizational citizenship behavior, prosocial motivation, psychological capital

Posted Date: July 1st, 2019

DOl: https://doi.org/10.21203/rs.2.10794/v1

License: (c) (1) This work is licensed under a Creative Commons Attribution 4.0 International License.

Read Full License 


\section{Abstract}

Background This study aims to sightsee the importance of organizational citizenship behavior in public and private hospitals of Pakistan. It is found imperative to discover the impact of prosocial motivation and psychological capital on organizational citizenship behavior. We also tried to investigate the role of workplace incivility as a moderator. Method We sampled the employees of public and private hospitals of Pakistan. All data were collected on-site during paid working hours without any kind of inference from the authors. Nurses and their immediate managers (i.e., doctors) were surveyed at two time points in order to minimize common method bias. At Time 1, 146 nurses completed survey on predictors (prosocial motivation, psychological capital) and moderator (workplace incivility). At Time 2, two weeks after Time 1, 35 doctors provide their perception about organizational citizenship behavior of nurses. Results Results showed that prosocial motivation has a trifling impact on organizational citizenship behavior when a high level of workplace incivility was observed. Conversely, psychological capital created a significant positive impact on organizational citizenship behavior, even when there was a lower level of workplace incivility exist. The results revealed that hospitals should strive for the minimal level of workplace incivility in order to improve the organizational citizenship behavior. Conclusions The hospitals should not tolerate the uncivil behaviors in order to ensure the high level of organizational citizenship behavior even at lower prosocial motivation levels. However, if nurses are prosocially motivated then the level of their organizational citizenship behaviors will be at its optimal level in the absence of workplace incivility which results in the ultimate benefit to patients. Furthermore, organizational citizenship behavior of nurses will be at optimal level in hospitals when they are equipped with hope, self-efficacy, optimism and resilience with the only condition that there must be low workplace incivility prevailed.

\section{Background}

With globalization and intense competition at the national and international level, the management of scarce organizational resources that can assist in promoting its competitiveness have become vital elements in the success of the hospital industry. Among these resources, human capital requires special consideration. Human resource assumes focal part in the service sector [1]. In hospital industry, patients' satisfaction is closely associated to hospital's staff organizational citizenship behavior (OCB) [2], therefore, there is a dire need to enhance OCB of employees working in hospitals [3]. OCB can be defined as work related behavior which is discretionary and beyond formal job responsibilities, neither specifically nor unequivocally acknowledged by the formal reward system [4].

While keeping in view from a motivational perspective, according to [5] prosocial motivation involves the desire of individuals' to engage in a helping behavior. Although a number of studies have explored the positive outcomes of employee motivation, but there is a lack of research on prosocial motivation [6]. Furthermore, psychological capital ensures employees' improved work engagement and commitment to the organization [7]. As per the previous studies are concerned, psychological capital is a potentially important factor for creating and improving OCB. Furthermore, it has been attempted to examine that whether psychological capital influences behaviors (e.g. performance and well-being) positively or not [8], 
however, literature is not adequately available in exploring this phenomenon [9]. High prosocial motivation and psychological capital will not only increase employee motivation to be engaged in extrarole behavior through high $\mathrm{OCB}$, but it will likewise add to the competitiveness of the hospital sector organization and prompt better future performance.

Academicians recently discussed workplace incivility at a foremost level as "deviant workplace behaviors which lead to rudeness, discourtesy, impoliteness and violation of the basic norms of workplace" [10]. Further, workplace incivility according to [11] have no optimistic concern for the rights, respects and feelings of others. Conversely to incivility, the construct OCB is positive in nature which has been demarcated by [12] as "individuals' behavior that is discretionary, not directly or explicitly recognized by the formal reward system, and that in aggregate promotes the effective functioning of the organization". Historically, organizations have attempted to ensure positive workplace outcomes by eliminating negative behaviors [13]. As per best of our knowledge, no study exists which elaborates the relationship of psychological capital and OCB, prosocial motivation and OCB, through the moderating role of workplace incivility. Thus, the conceptual model of this study is imperative to investigate.

The sector that was taken to check the OCB was hospitals, including public and private hospitals of Pakistan. The respondents of the study were doctors (supervisors) and nurses (subordinates). From behavioral perspective, [14] suggested that hospital and basic medical institutions should be taken into consideration while exploring the OCB of the employees in the medical center. [14] further explored that although large hospitals having scarce resources, yet are often overloaded with patients which enhance the need of citizenship behavior. In sum, leaders and supervisors are among the basic sources of influencing workplace attributes including psychological capital, prosocial motivation, workplace incivility and OCB. There is a deep relationship between the supportive behavior of the supervisors and the employees' growth [15] but when incivility by any means comes across the top, middle or lower level of management, it may weaken the same relationship, and may weaken the association between psychological capital and OCB. Consequently, the purpose of this research paper is twofold, as at the same time we attempt to explore the relationship between prosocial motivation and OCB and psychological capital and OCB.

\section{Prosocial motivation and organizational citizenship behavior}

Motivational basic perspective can better explain the view of prosocial motivation. Prosocial motivation is led by three-hierarchical level of motivation named as (i) global, (ii) contextual and (iii) situational [16]. In order to achieve the desired goals, it is considered essential for employees to get their dispositions direction from global motivation. Contextual motivation is changeable through specific terms and conditions as it focuses on the employees with a specific class of behavior working in a specific direction. On the other hand, Situational motivation is vastly changeable, paying attention on motivating employees to adopt a particular behavior in a specific time period. In contrast, prosocial motivation is based on the desire of an individual to benefit others" said by [5]. 
A prosocially motivated employee is energetic enough to help his colleagues which may ultimately establish a foundation of a good OCB. Consequently, OCB may depend on prosocial motivation significantly. A new category of OCB i.e. customer-oriented OCB has been proposed by [17] who defined it as "pattern of non-mandated and individual-initiated behaviors which make great efforts to develop customers' satisfaction and quality service delivery". A typical example of OCB includes anticipating one's problems and then trying to be equipped for fulfilling customers' needs and resolving their issues on a priority basis [17]. Likewise, it is claimed that the positive impact on the lives of others is possible through "Prosocial motivation" [18]. As highlighted previously, research has shown that a number of important work behaviors can be initiated through prosocially motivated individuals [19], for instance task persistence, and improved performance [18]. The employees equipped with prosocial motivation are always enthusiastic for the fulfillment of the goals of facilitating others [18]. Further, in order to build employees' citizenship behavior, it seems mandatory to have their motivational level high on the work place. Rewards, bonuses and incentives are the biggest source of motivation for the employees [20]. In the same perspective, [6] recently found the direct relation between prosocial motivation and OCB. Based on the above literature, we propose the following hypothesis:

Hypothesis 1: Prosocial motivation has positive impact on OCB.

\section{Psychological capital and Organizational Citizenship Behavior}

According to [21], there is sufficient literature on psychological capital published so for [22]. Correspondingly, each component of psychological capital have a significant role in facilitating the organizations to generate positive outcomes. psychological capital has been conceptually identified as "hope", "optimism", "self-efficacy" and "resilience" [23, 才. All of the dimensions of psychological capital mentioned above are considered as very helpful for the employees to have a very constructive and positive OCB in the organization. Self-efficacy is defined as, "an individual's trust in his/her capabilities to categorize and accomplish journey which is required to build certain achievements" [24]. Self-efficacy is positively associated with performance and job satisfaction [7]. Hope is symbolized as the effort to achieve the success through a skill to recognize, simplify and follow the method to success". It is probably true to claim that hopeful employees are psychologically strong enough to help others and ultimately are very motivated for a positive and constructive OCB in their workplace.

From attribution theory, optimism may be defined as "a provenance style that explains positive events through personal, permanent, and persistent attitudes" [9]. Optimism boosts self-esteem and morale of the employees which creates positive and constructive OCB in them [ 7 ] while Resilience is defined as "positive psychological capacity, which makes possible to ricochet from hardship, ambiguity and conflict and ultimately resulting in increased responsibility" [24]. This increased level of responsibility creates a very constructive and positive OCB.

[9] revealed that psychological capital promotes the improved work behaviors of the employees showing constructive OCB. Literature also provided support to a direct and indirect relationship of psychological 
capital with the workplace deviance through organizational identification. Therefore, we may say that psychological capital has a direct relationship with OCB. Thus, we may propose the following hypothesis:

Hypothesis 2: psychological capital has positive impact on OCB.

\section{Workplace incivility as a Moderator}

According to conservation of resource theory $[25,26]$, incivility creates destabilization in the instrumental support, including the phenomenon of information sharing, and usability of one's work expertise to help others. The resources mentioned above, always prosocially motivate the employees to manage their daily workload in the best possible way which relates their job performance and work involvement [27]. Once these resources are destabilized, good job performance cannot be expected. As in the relationship of the above discussion, we may say that workplace incivility acts as a moderator between job performance and job involvement, which is considered as the pre-requisite of a good citizenship behavior, therefore, it is most likely to say that the OCB of the employees would be badly affected in the presence of workplace incivility. We may take the example of a health care domain, where professional skills are very important for the survival of the whole setup and teams cannot be prosocially motivated without knowledge sharing, which is the ultimate resort of patient care and safety but uncivil behaviors damage the constructive outcome of the employees ensuring the decline of effective and supportive behaviors of them and their level of OCB.

When incivility is prevalent, colleagues may be less able to tap into their collective strengths to cope with their work stresses [24]. If they are not able to cope with their challenges, their feelings of job satisfaction will not be achieved, which describes their self-efficacy to have the best performance [7]. As per the above discussion, professional skills are very important to be shared among employees. It is probably true to claim that hopeful employees are psychologically strong enough to help others, but uncivil behaviors decrease their morale which eventually disrupts their level of OCB [7].

Socialization theory contributes to understanding OCBs. It claims that, within an organization, the individual socialization process helps employees to have the positive psychological capacity to recoil, 'bounce back' from adversity, vagueness and conflict resulting in increasing their accountability [24] and improving their OCB dimensions for achieving better outcomes. Workplace incivility has an effect on employees' outcome and the organization as a whole [28]. A variety of constructs have been engendered which are considered as the outcomes of the incivility at workplace e.g., social discouragement and workplace violent behavior [29]. The uncivil behaviors result in less attention towards work, which reduces their job performance ultimately [30]. Thus, it can be argued that workplace incivility may weaken the relationship between prosocial motivation and $\mathrm{OCB}$ and similarly creating the same impact on the relationship between psychological capital and OCB.

Hypothesis 3a: Workplace incivility moderates the association between prosocial motivation and OCB.

Hypothesis 3b: Workplace incivility moderates the association between psychological capital and OCB. 


\section{Method}

\section{Sample and Procedure}

For this study, we sampled the employees of public and private hospitals of Pakistan. All data was collected on-site during paid working hours without any kind of inference from the authors. Nurses and their immediate managers (i.e., doctors) were surveyed at two time points in order to minimize common method bias [31]. At T1, 146 nurses completed survey on predictors (Prosocial motivation, psychological capital) and moderator (workplace incivility) of the study. At T2 two weeks after T1, 35 doctors provide their perception about OCB of nurses. The Internal Review Board (IRB) of corresponding authors' university has approved this study. Nurses who worked with their doctors less than 6 months were not considered as participants of the surveys. Further, as number of Nurses varied from 3 to 10 in each department, henceforth, when there are at least three responses in a group then it is acceptable to aggregate [32].

Participants were employed in the emergency, radiology, pathology, cancer center, cardiac surgery, cardiology, clinical nutrition, dermatology, diabetes \& endocrinology, emergency care, ENT, gastroenterology, neurology and ophthalmology departments. For the purpose of data entry, the doctors and nurses Surveys were coded in order to allow matching of surveys linking subordinates to their supervisor. Both anonymity and confidentiality were ensured to the participants of this study before they agreed to participate.

\section{Measures}

Prosocial Motivation: We employed prosocial motivation scale developed by [18] having ' 5 ' items. Sample item included "I get energized by working on tasks that have the potential to benefit others". Participants by using 5 -point Likert scale indicated their level of prosocial motivation where " $1=$ strongly disagree" and " $5=$ "strongly agree". A high score showed employees highly prosocially motivated and vice versa. Data collection of prosocial motivation were reliable because the value of Cronbach's Alpha was 0.79 which is greater than the minimum accepted value i.e. 0.70 .

Workplace Incivility: Workplace incivility was measured with a scale developed by [28] comprised of 7items. For this purpose, there are four items on ignoring individuals and three items on perceived judgment. A sample of item on ignoring is "ignored or excluded you from professional camaraderie" on the other hand, a sample of item on judgment is "Doubted your judgment on a matter over which you have responsibility"? Questionnaire tool is measured by "5-point Likert scale" where 1="never" and 
$5=$ "frequently". The value Cronbach's Alpha was 0.80 which is greater than 0.70 , so the data were reliable to proceed further for data analysis.

Organizational citizenship behavior (OCB): We used the 7-item scale to measure customer-oriented OCB developed by [33]. Sample item included "This employee is assisting co-workers to deliver high-quality customer oriented services". The level of OCB of participants of this study measured with 5-point Likert scale where $1=$ "never" and $5=$ "frequently". A high score revealed employees high in OCB and vice versa. The Cronbach's Alpha value of OCB was 0.75 reveal that the data were reliable for further analysis.

Psychological Capital: To measure psychological capital of nurses, we used 12-item scale developed by [7]. A Sample item included "I feel confident presenting information to a group of colleagues". PCQ tool was measured by 5 point numeric scale ranged from "not at all Satisfied" to "very Satisfied" where 1 indicated "not at all satisfied" and 5 indicated "very satisfied". A high score on the PCQ revealed a higher level of psychological capital of individuals at workplace and vice versa. Before using the collected data for results and interpretation in the main study according to other questionnaire tools, the Cronbach's Alpha of PsyCap was also checked i.e. 0.83 which was $>0.70$.

\section{Results}

Correlational analysis was carried out for the initial testing of study hypotheses. The correlation analysis revealed that OCB has significant positive correlation with psychological capital $(r=0.39, p<0.01)$ and prosocial motivation $(r=0.42, p<0.01)$. In turn, OCB has significant negative correlation with workplace incivility $(r=-0.40, p<0.01)$. Furthermore, both independent variables (see Table 1$)$ have a significant relationship with the workplace incivility which is taken as moderator in this study.

Table 1: Correlation Analysis

Since data were collected from multi source thus, to test the study hypotheses the linear regression modeling was used. In this perspective, at level 1 prosocial motivation and OCB were tested. Workplace incivility and OCB were investigated at level 2 , whereas, the moderating impact of workplace incivility was tested at level 3 (see Figure 1). When employees are nested within departments, then linear regression modeling is considered as an appropriate method to check influence of variables on one another. Further, before administering the linear regression modeling, multi-collinearity and normality of data were checked. The data we used in this study were suitable for regression because it was observed that tolerance values were above the generally accepted value 0.10 [34].

The first hypothesis $(\mathrm{H} 1)$ based on quandary that there could be a positive relationship between prosocial motivation and OCB. Linear regression analysis (given in Table 1) shows that model is significant and prosocial motivation cause $17.3 \%$ change in OCB with a significant positive effect $(\beta=0.42, p<0.01)$. Thus, our first hypothesis $(\mathrm{H} 1)$ was accepted. The second hypothesis $(\mathrm{H} 2)$ based on the positive relationship between psychological capital and OCB. In this case, linear regression analysis (see Table 2) 
shows that model is significant and psychological capital cause $14.7 \%$ change in OCB with a significant positive effect $(\beta=0.38, p<0.01)$. Therefore, our second hypothesis $(H 2)$ was also accepted.

Table 2: Linear Regressions

Third Hypotheses ( $\mathrm{H} 3 \mathrm{a}$ and $\mathrm{H} 3 \mathrm{~b}$ ), which was based on the moderating impact of workplace incivility on the relationship between prosocial motivation and $\mathrm{OCB}$; and between psychological capital and OCB, were tested through linear regression moderation analysis. Especially In cross level case it is very hard to obtain significant interaction [35], However, in our study (see Table 3) prosocial motivation has not only direct significant relationship with $\mathrm{OCB}$, but it was also significant in the presence of moderator i.e. workplace incivility $(\beta=0.17, p<0.01)$.. The overall model was significant when workplace incivility was taken as moderator between prosocial motivation and OCB. Hence our third hypothesis $(\mathrm{H} 3 \mathrm{a})$ is accepted.

Table 3: Moderation Analysis with Prosocial Motivation

Similarly, moderation analysis in Table 4 shows that when workplace incivility acts as a moderator between psychological capital and OCB then there comes a significant relationship with $(\beta=0.04, p<0.01)$ that results in an overall change of $2.2 \%(F-s i g=0.00)$ OCB of employees at workplace. Hence our hypothesis $H 3 b$ accepted as well. Table 4 is revealing that there exist moderation influence but the intensity of moderation can't be checked from the table directly. Hence, to check out impact with the intensity of workplace incivility on the relationships of prosocial motivation and OCB; and between psychological capital and OCB, the moderation line graph is given in the discussion portion (see Figure 2 and Figure 3).

Table 4: Moderation Analysis with Psychological Capital

\section{Discussion And Conclusion}

$\mathrm{OCB}$, which is the dependent variable in our study, has a crucial role in health sector [36]. The literature review revealed that only a few studies have focused on OCB among nurses [37]. The importance of OCB is higher not only for practitioners, but for academicians perspective as well because OCB brings fruitful consequences of both employees and the organization such as high job performance [38], and high job satisfaction [1].

We tested the cross-level interaction of workplace incivility with prosocial motivation of nurses on OCB. From Figure 02, we can have the clear demonstration of hypothesis $\mathrm{H} 3 \mathrm{a}$ that in the presence of low workplace incivility, the line graph is flattered which reveals that low level of prosocial motivation ensures the high level of OCB but with the low increasing rate in OCB. Consequently, the hospitals should not tolerate the uncivil behaviors in order to ensure the high level of OCB even at lower prosocial motivation levels. However, if nurses are prosocially motivated then the level of their OCBs will be at its optimal level in the absence of workplace incivility which results in the ultimate benefit to patients. 
Insert Figure 02: Moderation Line Graph with Prosocial Motivation

Further, we tested the cross-level interaction of workplace incivility with psychological capital of nurses on OCB. From the moderation findings (see Figure $03 \& 04$ ) the hypothesis $\mathrm{H} 3 \mathrm{~b}$ is supported by indicating that OCB of nurses is low at lower level of psychological capital, but OCB gets improved when nurses are equipped with hope, self-efficacy, optimism and resilience, at high workplace incivility. On the contrary, OCB shifts upward, revealing that even at lower level psychological capital, the OCB is high even on the same level of incivility. Furthermore, in order to discuss the intensity of change 'a cluster column chart' (see Figure 4) is given below which reveals the same results as discussed above for Figure 03. Thus, OCB of nurses will be at optimal level in hospitals when they are equipped with hope, self-efficacy, optimism and resilience with the only condition that there must be low workplace incivility prevailed. As it seems difficult to understand accurately the Figure 03 because both lines are seemed as almost parallel, thereby Figure 04 (a cluster column chart) has been drawned to better understand the role of moderator (workplace incivility).

Insert Figure 03: Moderation Line Graph with Psychological Capital

Insert Figure 04: A Clustered Column Chart

\section{Research limitations and future research suggestions}

This study is limited from following aspects such as generalizability of finding, sampling, and cultural context. For instance, due to idiosyncratic characteristics of research location, the generalizability of the finding may be limited. Furthermore, the sample includes majority of the respondents from private hospitals [14] which also limits the generalizability of study findings. It is also obvious that nurses mostly deal with the aging people in the hospitals [14] thereby, there might be bias in the results. Also the other staff of the hospital e.g. admin staff, helper staff were not a part of this study. Further studies should deal with not only large, but medium and small hospitals including staff other than nurses and doctors as well so that sampling could be rationale and free of biasness.

The OCB's sensitivity level may be affected due to unique culture thus future studies may test our proposed model at cross-cultural level. For instance, academician can focus other under developing 
countries of world as well. Furthermore, a comparative study on the public and private hospitals could generate the valuable results.

\section{Abbrevations}

OCB: Organizational Citizenship Behavior PsyCap: Psychological Capital ENT: Ears, Nose and Throat PCQ: Psychological Capital Questionnaire T1: Time 1 T2: Time 2

\section{Declation}

I confirm that I have read BioMed Central's guidance on competing interests and none of the authors have any competing interests. Further, I can confirm I have included the data and material in this manuscript. Data Sheet will be provided seperatly on demand.

\section{Acknowledgement}

We would like to express our warm thanks to Dr. Talat Islam (Assistant Professor at Instittute of Business Administration, Punjab University) who supported us at every point along the way, and without whom it would have been impossible to accomplish the end result in such a successful manner. Moreover, especially, his conceptual contribution is highly appreciated.

\section{Funding}

There is no funding for this manuscript.

\section{Availability of data and materials}

The datasets used and/or analyzed during the current study are available from the corresponding author on reasonable request.

\section{Authors' contributions}

Dr. Ghulam Abid contributed to the original design of the study. The data collection was carried out by corresponding author that is Mr. Muhammad Nawaz who participated in the data analysis and interpretation of the data as well. The manuscript was written by Muhammad Nawaz and Dr. Ghulam Abid and was edited by both authors, who also approved of the final manuscript.

\section{Ethics approval and consent to participate}


Ethical approval was provided by the research commette of National College of Business Administration \& Economics, Lahore. All participants gave their written informed consent to participate in the study.

\section{Consent for publication}

Not applicable.

\section{References}

1. Nadiri, H., \& Tanova, C. (2010). An investigation of the role of justice in turnover intentions, job satisfaction, and organizational citizenship behavior in hospitality industry. International Journal of Hospitality Management, 29(1), 33-41. https://doi.org/10.1016/j.jijm.2009.05.001

2. Kaya, S. D., lleri, Y. Y., \& Yuceler, A. (2016). Importance of hospital way-finding system on patient satisfaction. Business Challenges in the Changing Economic Landscape, 2(1), 33-40.

3. Kaihatu, T. S., \& Djati, S. P. (2016). Organizational Citizenship Behavior (Ocb), Service Quality, And Patient Satisfaction: A Case Study Of The Nurses In Private Hospitals Of Surabaya. Journal iLmiah Manajemen, 6(2), 213-227.

4. Shin, Y., Kim, M. S., Choi, J. N., Kim, M., \& Oh, W. K. (2017). Does leader-follower regulatory fit matter? The role of regulatory fit in followers' organizational citizenship behavior. Journal of Management, 43(4), 1211-1233.

5. Shdo, S. M., Ranasinghe, K. G., Gola, K. A., Mielke, C. J., Sukhanov, P. V., Miller, B. L., \& Rankin, K. P. (2016). Deconstructing empathy: Neuroanatomical dissociations between affect sharing and prosocial motivation using a patient lesion model. Neuropsychologia, https://doi.org/10.1016/j.neuropsychologia.2017.02.010

6. Hu, J., \& Liden, R. C. (2012). Making a difference in the teamwork: Linking team prosocial motivation to team processes and effectiveness. Academy of Management Journal, 48(4), 1102-1127.

7. Luthans, F., Avolio, B. J., Avey, J. B., \& Norman, S. M. (2007). Positive Psychological Capital: Measurement and Relationship with Performance and Satisfaction Positive Psychological Capital. Personal Psychology, 60(1), 541-572.

8. Luthans, F., Avey, J. B., Clapp-Smith, R., \& Li, W. (2008). More evidence on the value of Chinese workers' psychological capital: A potentially unlimited competitive resource? The International Journal of Human Resource Management, 19(5), 818-827. https://doi.org/10.1080/09585190801991194

9. Avey, J. B., Luthans, F., \& Youssef, C. M. (2010). The Additive Value of Positive Psychological Capital in Predicting Work Attitudes and Behaviors. Journal of Management, 36(2), 430-452. 
https://doi.org/10.1177/0149206308329961

10. Hershcovis, M. S., Ogunfowora, B., Reich, T. C., \& Christie, A. M. (2017). Targeted workplace incivility: The roles of belongingness, embarrassment, and power. Journal of Organizational Behavior, 38(7), 10571075.

11. Cortina, L. M. (2008). Unseen injustice: Incivility as modern discrimination in organizations. Academy of Management Review, 33(1), 55-75. https://doi.org/10.5465/AMR.2008.27745097

12. Turnipseed, D. L. (2018). Emotional Intelligence and OCB: The Moderating Role of Work Locus of Control. The Journal of Social Psychology, 158(3), 332-336, 00224545.2017.1346582. https://doi.org/10.1080/00224545.2017.1346582

13. Normand, S., Ambrosoli, J., Guiet, J., Soucisse, M. M., Schneider, B. H., Maisonneuve, M. F., Lee, M.D., \& Tassi, F. (2017). Behaviors associated with negative affect in the friendships of children with ADHD: An exploratory study. Psychiatry Research, 247(1), 222-224.

https://doi.org/10.1016/j.psychres.2016.11.041

14. Luo, L., Luo, L., He, X., Zhang, X., \& Shi, Y. (2016). Effects of distance on health seeking behaviors of outpatients in China 's large hospitals: case of West China hospital of Sichuan university, International Journal of Clinical and Experimental Medicine, 9(6), 11923-11933.

15. Sonenshein, S., Dutton, J. E., Grant, A. M., Spreitzer, G. M., \& Sutcliffe, K. M. (2013). Growing at Work: Employees' Interpretations of Progressive Self-Change in Organizations. Organization Science, 24(2), 552-570. https://doi.org/10.1287/orsc. 1120.0749

16. Van Yperen, N. W., Wörtler, B., \& De Jonge, K. M. M. (2016). Workers' intrinsic work motivation when job demands are high: The role of need for autonomy and perceived opportunity for blended working. Computers in Human Behavior, 60(2), 179-184. https://doi.org/10.1016/j.chb.2016.02.068

17. Dimitriades, Z. S. (2007). The influence of service climate and job involvement on customer-oriented organizational citizenship behavior in Greek service organizations: a survey. Employee Relations, 29(5), 469-491. https://doi.org/10.1108/01425450710776290

18. Grant, A. M., \& Sumanth, J. J. (2009). Mission possible? The performance of prosocially motivated employees depends on manager trustworthiness. Journal of Applied Psychology, 94(4), 927-944. https://doi.org/10.1037/a0014391

19. De Dreu, C. K. W., \& Nauta, A. (2009). Self-interest and other-orientation in organizational behavior: Implications for job performance, prosocial behavior, and personal initiative. Journal of Applied Psychology, 94(4), 913-926. https://doi.org/10.1037/a0014494

20. Warneken, F., \& Tomasello, M. (2008). Extrinsic rewards undermine altruistic tendencies in 20-montholds. Developmental Psychology, 44(6), 1785-1788. https://doi.org/10.1037/a0013860 
21. Avey, J. B., Reichard, R. J., Luthans, F., \& Mhatre, K. H. (2011). Meta-analysis of the impact of positive psychological capital on employee attitudes, behaviors, and performance. Human Resource Development Quarterly, 22(2), 127-152. https://doi.org/10.1002/hrdq.20070

22. Lopez, S. J., \& Snyder, C. R. (2009). Oxford Handbook of Positive Psychology, 752. Retrieved from http://books.google.com/books?hl=en\&lr=\&id=NWF-AwAAQBAJ\&pgis=1

23. Luthans, F., \& Youssef, C. M. (2004). Human, social, and now positive psychological capital management: Investing in people for competitive advantage. Organizational Dynamics, 33(2), 143-160. https://doi.org/10.1016/j.orgdyn.2004.01.003

24. Luthans, F. (2002). Positive organizational behavior: Developing and managing psychological strengths. Academy of Management Executive, 16(1), 57-72.

https://doi.org/10.5465/AME.2002.6640181

25. Hobfoll, S. E. (2001). The Influence of Culture, Community, and the Nested-Self in the Stress Process: Advancing Conservation of Resources Theory. Applied Psychology: An International Review, 50(3), 337421. https://doi.org/10.1111/1464-0597.00062

26. Halbesleben, J. R. B. (2006). Sources of Social Support and Burnout: A Meta-Analytic Test of the Conservation of Resources Model. Journal of Applied Psychology, 91(5), 1134-1145. https://doi.org/10.1037/0021-9010.91.5.1134

27. Chiaburu, D. S., \& Harrison, D. a. (2008). Do peers make the place? Conceptual synthesis and metaanalysis of coworker effects on perceptions, attitudes, OCBs, and performance. The Journal of Applied Psychology, 93(5), 1082-103. https://doi.org/10.1037/0021-9010.93.5.1082

28. Cortina, L. M., Magley, V. J., Williams, J. H., \& Langhout, R. D. (2001). Incivility in the workplace: Incidence and impact. Journal of Occupational Health Psychology, 6(1), 64-80.

https://doi.org/10.1037/1076-8998.6.1.64

29. Duffy, M. K., Ganster, D. C., \& Pagon, M. (2002). Social undermining in the workplace. Academy of Management Journal, 45(2), 331-351. https://doi.org/10.2307/3069350

30. Porath, C. L., \& Pearson, C. M. (2010). The Cost Of Bad Behavior. Organizational Dynamics, 39(1), 6471. https://doi.org/10.1016/j.orgdyn.2009.10.006

31. Min, H., Park, J., \& Kim, H. J. (2016). Common method bias in hospitality research: A critical review of literature and an empirical study. International Journal of Hospitality Management, 56(1), 126-135. https://doi.org/10.1016/j.jhm.2016.04.010

32. Choi, J. N. (2007). Change-oriented organizational citizenship behavior: effects of work environment characteristics and intervening psychological processes. Journal of Organizational Behavior, 28(4), 467484. https://doi.org/10.1002/job 
33. Wu, L.-Z., Tse, E. C.-Y., Fu, P., Kwan, H. K., \& Liu, J. (2013). The Impact of Servant Leadership on Hotel Employees' "Servant Behavior." Cornell Hospitality Quarterly, 54(4), 383-395.

https://doi.org/10.1177/1938965513482519

34. Fidell, S., Tabachnick, B., Mestre, V., \& Fidell, L. (2013). Aircraft noise-induced awakenings are more reasonably predicted from relative than from absolute sound exposure levels. The Journal of the Acoustical Society of America, 134(5), 3645-53. https://doi.org/10.1121/1.4823838

35. McClelland, G. H., \& Judd, C. M. (1993). Statistical difficulties of detecting interactions and moderator effects. Psychological Bulletin, 114(2), 376-390. https://doi.org/10.1037/0033-2909.114.2.376

36. Raub, S. (2008). Does bureaucracy kill individual initiative? The impact of structure on organizational citizenship behavior in the hospitality industry. International Journal of Hospitality Management, 27(2), 179-186. https://doi.org/10.1016/j.ijhm.2007.07.018

37. Yu, H. Y., Lou, J. H., Eng, C. J., Yang, C. I., \& Lee, L. H. (2016). Organizational citizenship behaviour of men in nursing professions: Career stage perspectives. Collegian, 25(1), 19-26, https://doi.org/10.1016/j.colegn.2017.02.003

38. Chiang, C.-F., \& Hsieh, T.-S. (2012). The impacts of perceived organizational support and psychological empowerment on job performance: the mediating effects of organizational citizenship behavior. International Journal of Hospitality Management, 31(1), 180-190. https://doi.org/10.1016/j.ijhm.2011.04.011

\section{Tables}

Table 1: Correlation Analysis

\begin{tabular}{llcccl}
\hline$\#$ & \multicolumn{1}{c}{ Variables } & $\mathbf{1}$ & $\mathbf{2}$ & $\mathbf{3}$ & $\mathbf{4}$ \\
\hline $\mathbf{1}$ & Workplace Incivility & 1 & & & \\
$\mathbf{2}$ & Prosocial Motivation & $-0.41^{* *}$ & 1 & & \\
$\mathbf{3}$ & Psychological Capital & $0.43^{* *}$ & $0.62^{* *}$ & 1 & \\
$\mathbf{4}$ & Organizational Citizenship Behavior & $-0.40^{* *}$ & $0.42^{* *}$ & $0.39^{* *}$ & 1 \\
\hline
\end{tabular}

Note: ${ }^{* *} \mathrm{p}<0.01$

Table 2: Linear Regressions 


\begin{tabular}{ccccc}
\hline Variable & $\mathbf{R}^{2}$ & $\boldsymbol{\beta}$ & $\mathbf{F}$ & F-sig \\
\hline Workplace Incivility & 0.16 & $-0.40 *$ & 34.86 & 0.00 \\
Prosocial Motivation & 0.17 & $0.42 *$ & 37.56 & 0.00 \\
Psychological Capital & 0.15 & $0.38 *$ & 30.77 & 0.00 \\
\hline
\end{tabular}

Dependent Variable: Organizational Citizenship Behavior, ${ }^{*} \mathrm{p}<0.05$

Table 3: Moderation Analysis with Prosocial Motivation

\begin{tabular}{|c|c|c|c|}
\hline \multirow[t]{3}{*}{ Variables } & \multicolumn{3}{|c|}{ Outcome } \\
\hline & \multicolumn{3}{|c|}{ Organizational Citizenship Behavior } \\
\hline & $\beta$ & $\mathrm{R}^{2}$ & F-sig \\
\hline Independent & & 0.25 & 0.00 \\
\hline Prosocial Motivation & $-0.05^{*}$ & & \\
\hline \multicolumn{4}{|l|}{ Moderator } \\
\hline Workplace Incivility & -0.95 & & \\
\hline \multicolumn{4}{|l|}{ Interaction } \\
\hline Prosocial Motivation $\times$ Workplace Incivility & $0.17 *$ & & \\
\hline
\end{tabular}

Table 4: Moderation Analysis with Psychological Capital

\begin{tabular}{|c|c|c|c|}
\hline \multirow[t]{3}{*}{ Variables } & \multicolumn{3}{|c|}{ Outcome } \\
\hline & \multicolumn{3}{|c|}{ Organizational Citizenship Behavior } \\
\hline & $\beta$ & $\mathrm{R}^{2}$ & F-sig \\
\hline Independent & & 0.22 & 0.000 \\
\hline Psychological Capital & $-0.22 *$ & & \\
\hline \multicolumn{4}{|l|}{ Moderator } \\
\hline Workplace Incivility & -0.47 & & \\
\hline \multicolumn{4}{|l|}{ Interaction } \\
\hline Psychological Capital $\times$ Workplace Incivility & $0.04 *$ & & \\
\hline
\end{tabular}


Figures

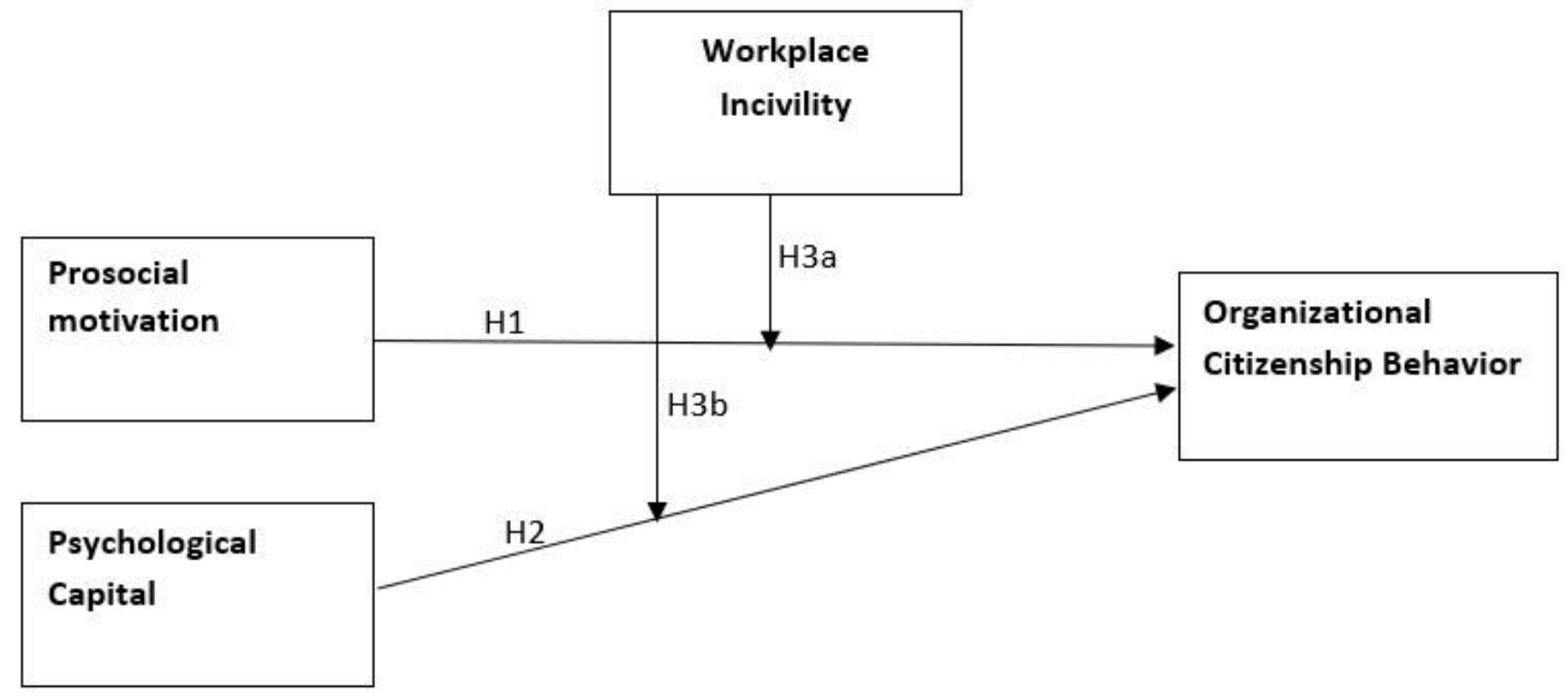

Figure 1

Conceptual Model 


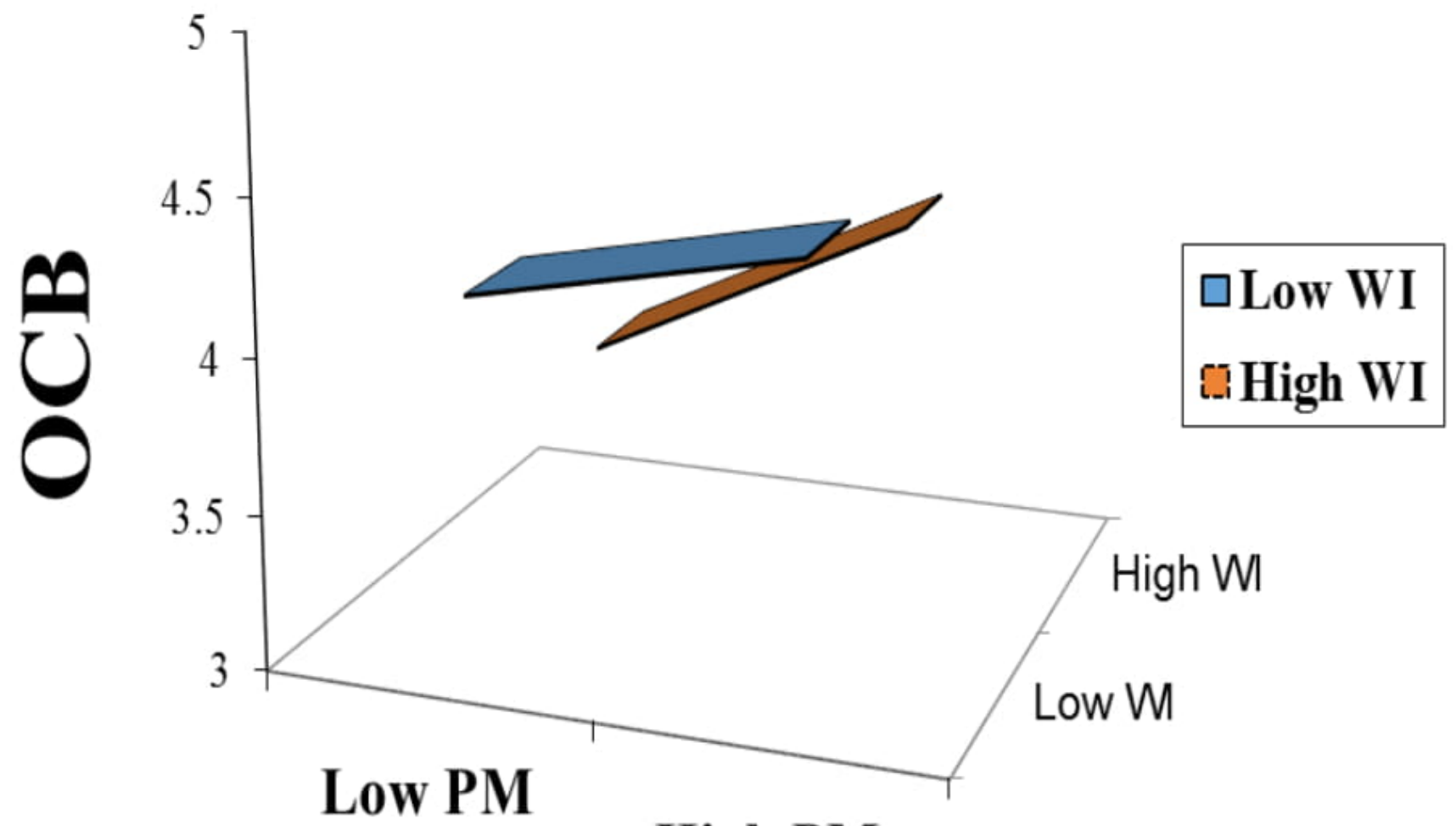

High PM

Figure 02: Moderation Line Graph with Prosocial Motivation

Figure 2

Moderation Line Graph with Prosocial Motivation 


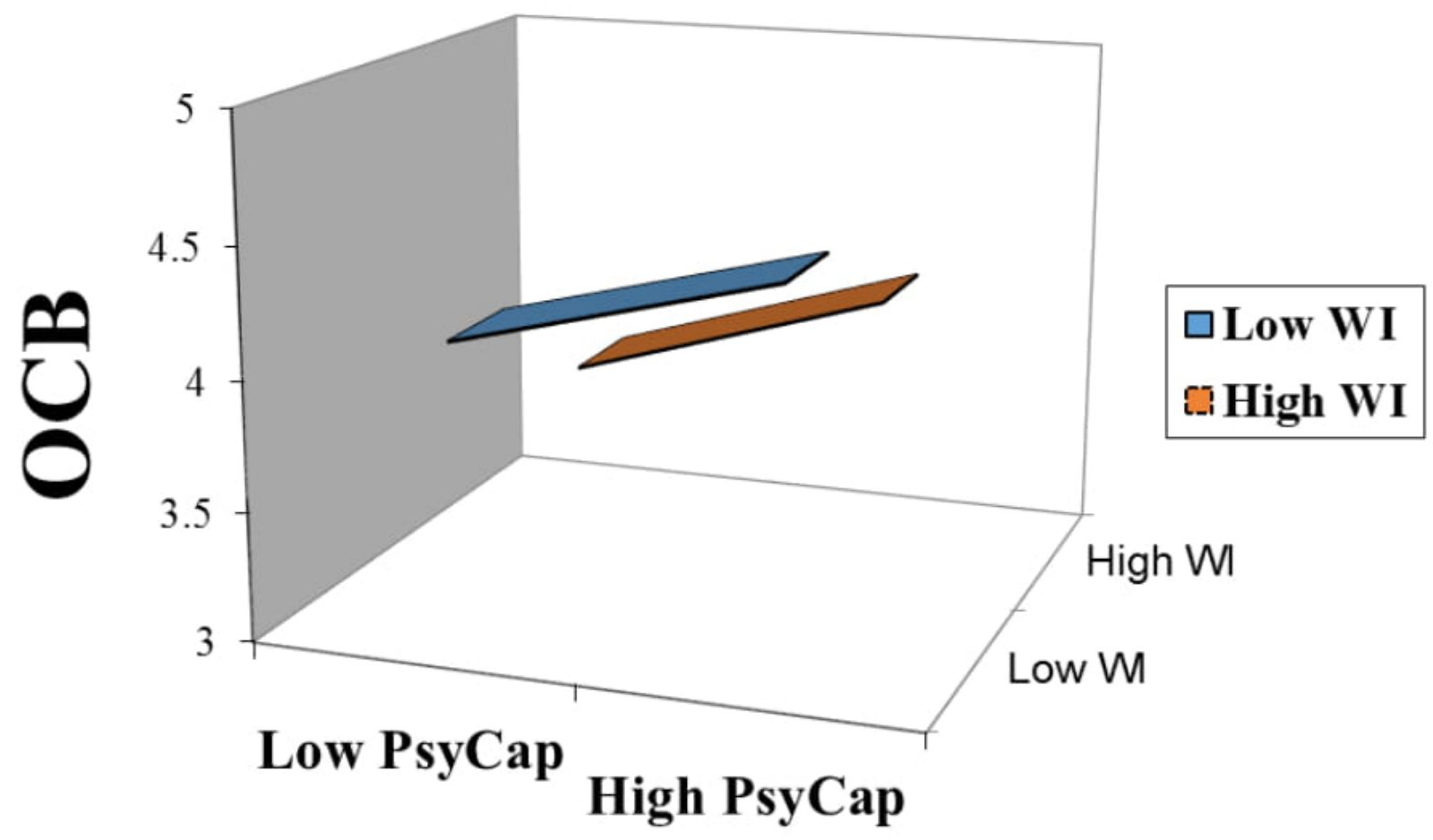

Figure 03: Moderation Line Graph with Psychological Capital

Figure 3

Moderation Line Graph with Psychological Capital 


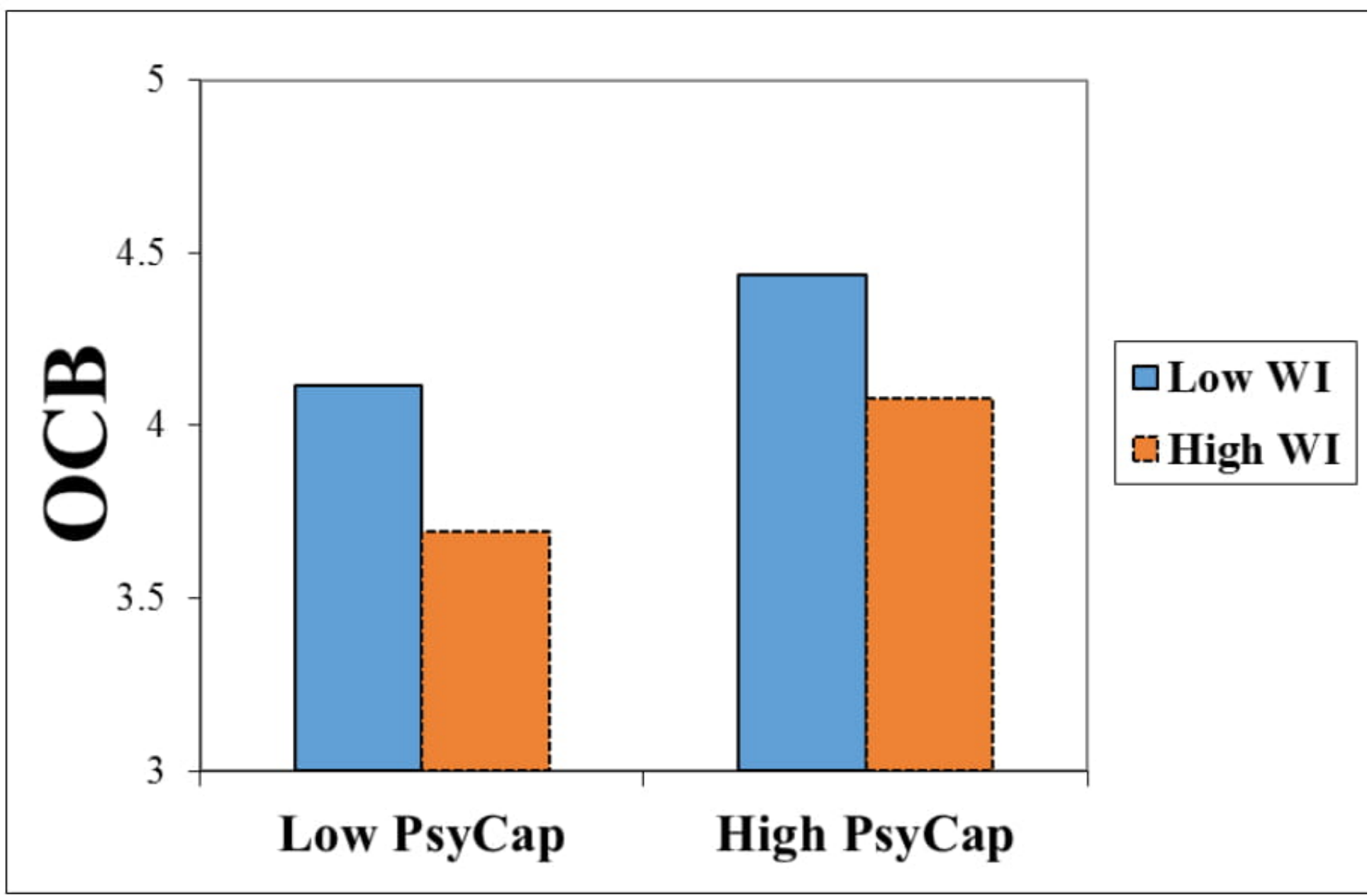

Figure 04: A Clustered Column Chart

Figure 4

A Clustered Column Chart 